\section{Kranke Ärzte}

\section{Schwerer Schritt zurück in die Praxis}

- Wenn der Arzt zum Patienten wird, kann er diese Doppelrolle oft nur schwer bewältigen und selbst sein Umfeld scheint irritiert. Vor allem nach längerer Krankheit ist der Weg zurück in den medizinischen Alltag oft mit einigen Hürden gespickt. Das zeigte eine qualitative Studie aus Großbritannien [Henderson $M$ et al. BMJ Open 2012; 2:e001776]. Die Teilnehmer waren im vorangegangenen Jahr mindestens sechs Monate aufgrund von Verletzungen, Depressionen oder Alkoholabhängigkeit nicht in ihrem Beruf tätig gewesen.

Die Befragung zeigte deutlich:Viele der Ärzte definierten ihre Person über ihre Arbeit. So änderte sich mit der Krankheit auch die eigene Identität, die ohne den täglichen Patientenkontakt immer mehr zu verschwinden drohte. Viele Ärzte gaben an, dass sie sich einsam und traurig fühlten, seit sie nicht mehr arbeiteten. Obwohl einige über eine unterstützende Haltung in der direkten Umgebung berichteten, klagten andere auch über negative Reaktionen vonseiten der Familie und der Freunde. Einige der Befragten hielten ihre Probleme deshalb lieber geheim. Durch die Kollegen erfuhren die kranken Ärzte zum Teil wenig Unterstützung und fürchteten sich deshalb vor ablehnenden Reaktionen bei ihrer Rückkehr an den Arbeitsplatz. Viele Ärzte neigten dazu, sich selbst die Schuld für ihre gesundheitliche Situation zu geben.

Das größte Hindernis für eine Rückkehr in den Alltag als Arzt war für die Befragten wohl das negative Selbstbild, sobald sie die Krankheit als Teil ihrer Identität begriffen hatten, meinen die Autoren. Um dem entgegenzuwirken, muss das Umdenken bereits in der Ausbildung beginnen, fordern die Autoren. Mediziner müssen erkennen, dass auch sie nicht unverwundbar sind.

Dr. Christine Starostzik

\title{
Mikronährstoffe
}

\section{Jungbrunnen für Spermien}

— Bei älteren Männern verschlechtert sich
die Spermienqualität: Vor allem in der DNA
häufen sich Fehler, unter anderem weil im
Alter die Schutzmechanismen nachlassen,
die das Erbgut vor oxidativem Stress bewah-
ren. Ob ein Plus an Vitaminen und Spuren-
elementen dem entgegenwirkt, wurde an 80
Männern im Alter von 20 bis 80 Jahren, alle
Nichtraucher, überprüft [Schmid TE et al.
Fertil Steril 2012; $98: 1130-7]$.
Und die Antioxidanzien zeigten Wirkung:
Bei Männern mit der höchsten täglichen
Vitamin-C-Dosis (459-3.370 mg/dl) im Ver-
gleich zu denjenigen mit der geringsten
Vitamin-C-Aufnahme pro Tag ( 26 - 99 mg/
dl) lag der Anteil erbgutgeschädigter Sper-
mien um $16 \%$ niedriger. Ein ähnlicher Zu- sammenhang ließ sich auch für Vitamin $E$, Folsäure und das Spurenelement Zink nachweisen, nicht jedoch für Beta-Karotin. Von den Mikronährstoffen profitierten überwiegend die älteren Probanden. Bei optimaler Versorgung hatten sie eine ähnlich gute Spermienqualität wie jüngere Männer. Diese profitierten hingegen nicht von höheren Vitamin-Dosen.

Männer ab 40 Jahren können nach Meinung der Studienautoren mit ausreichend Vitamin C, Vitamin E, Folsäure und Zink DNA-Schäden der Spermien vorbeugen. Ob das auch die Fruchtbarkeit steigert und die Gesundheit der Nachkommen verbessert, könne zum jetzigen Zeitpunkt nicht beantwortet werden.
Dr. Dagmar Kraus

\section{OVG-Urteil}

\section{Kein Daueranspruch auf Spermienkonservierung}

\begin{abstract}
— Die Heilfürsorge für Beamte muss die dauerhafte Lagerung eingefrorener Samenzellen nicht zahlen. Bedingung dafür ist, dass der Anlass für die Kryokonservierung wie eine Erkrankung nicht mehr gegeben ist. Das hat das Niedersächsische Oberverwaltungsgericht (OVG) in Lüneburg mit einem kürzlich veröffentlichten Beschluss entschieden [Az.: 5 LA 247/11].
\end{abstract}

Dies gilt auch, wenn die Kosten für das Einfrieren zunächst übernommen worden waren. Im konkreten Fall war der Kläger an einem Prostatakarzinom erkrankt. Nach einer radikalen Prostatektomie sollte er eine Chemotherapie erhalten. Weil er sich sorgte, er könne dauerhaft unfruchtbar werden, hatte er vorher Spermien einfrieren lassen. Die Kosten für die Kryokonservierung hatte die Heilfürsorge - die Krankenversicherung für einen Teil der Beamten, vor allem Polizisten - getragen. Die Unfruchtbarkeit trat nicht ein. Daher lehnte die Heilfürsorge die weitere Kostenübernahme für das Einfrieren ab. Zu Recht, wie das OVG entschied. In solchen Fällen könne es zwar „im Zuge einer umsichtigen Familienplanung sinnvoll sein, die gewonnenen Samenzellen weiter aufzubewahren“, erklärten die Richter. „Dies dient jedoch nicht der Linderung krank-

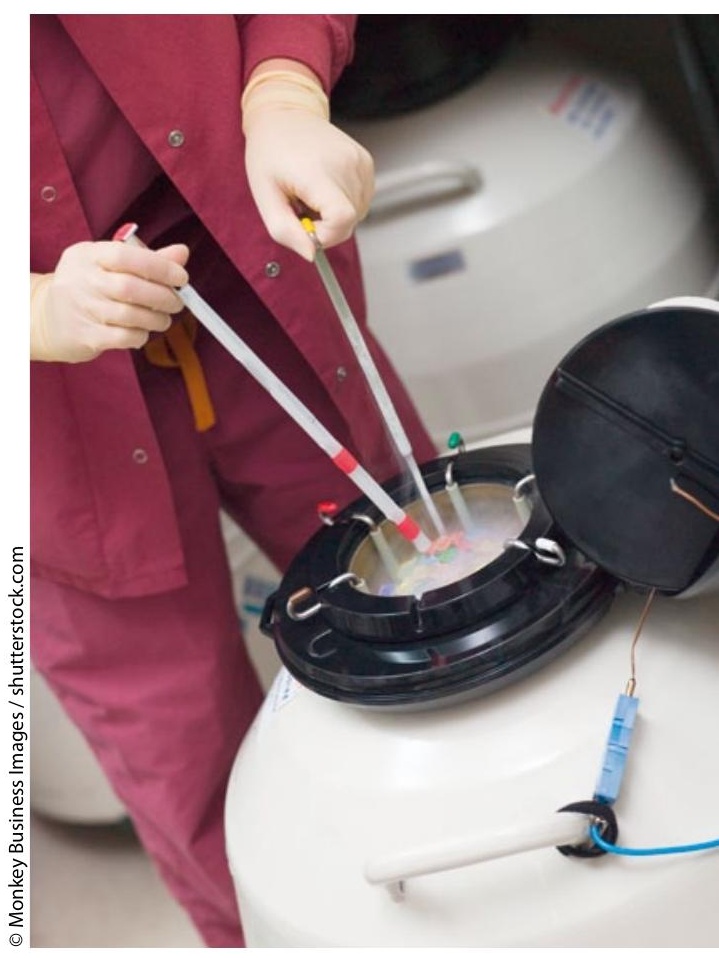

heitsbedingter körperlicher Beeinträchtigungen." Ein Kostenerstattungsanspruch gegenüber der Heilfürsorge bestehe daher nicht. Martin Wortmann 